treated as running through the lattice as a whole independently of each other, and the London-HeitlerHeisenberg model, in which the electrons are supposed to be bound to individual atoms and to move only by changing places. The relation between these models was discussed by Néel, Stoner, Mott and others, but remains by no means clear. It may, however, be of interest to give the description of a ferromagnetic metal or alloy which emerged from the discussions.

A metal such as nickel must be thought of as a mixture of ions in different states, $(3 d)^{10},(3 d)^{9}$ and perhaps higher states of ionization. The conduction electrons move freely among the ions, and number about 0.6 to 0.7 per atom. The elementary magnets are the 'holes' or vacant places in the nearly completed shells of the ions. The holes in the ions are continually moving about from ion to ion; to this motion is ascribed the large electronic specific heats observed in iron, nickel, palladium and platinum at helium temperatures. If ions with the configurations $(3 d)^{8}$ are present, then pairs of coupled spins with a moment of two Bohr magnetons will move through the crystal. The possible energy states for these holes, or pairs of holes, form bands with an energy spread of about 3 electron volts, as shown by experiments on soft X-rays (Farineau, Skinner). However, there may well be strong correlation forces which prevent more than one elementary magnet from ever being in one atom. If this is the case the correct model for a ferromagnetic material would seem to be of the Heisenberg type, modified to take account of the fact that the number of lattice points is greater than the number of magnets, a fact which allows the free motion of the magnets (holes) already referred to. An interesting first step in this direction has been taken by Stoner, who has worked out the effect of introducing a Weiss intramolecular field into the collective electron treatment.

For nickel and nickel-rich alloys the total number of positive holes in the $d$ shells is equal to the saturation moment in Bohr magnetons ; the report of Néel showed very clearly that this cannot be the case for iron. Here the ions must be present in a large number of different states of ionization, and only some of them give a positive exchange integral and thus a contribution to the ferro-magnetism.

There were interesting discussions on what happens to the orbital moment in ferromagnetic materials, evidence being drawn from the gyromagnetic effect (Sucksmith, Barnett) and from the saturation moments of alloys (Forrer). From the theoretical point of view this problem remains quite obscure.

Becker, Sucksmith and Gerlach gave results bearing on the magnetization curves of ferromagnetic materials. A large number of facts seem to indicate that a small piece of material has a high coercive force. According to Becker, a magnetized material contains nuclei at which demagnetization can start, and such nuclei would not be present in a small specimen; but no explanation could be given of the nature of these nuclei.

The diamagnetism of aromatic crystals was discussed by Krishnan, in particular their magnetic anisotropy. As pointed out by F. London, the 'orbit' responsible for the diamagnetism in naphthalene, anthracene and so on must extend over the whole molecule.

\title{
Work of the Discovery Committee
}

\section{Fifth Commission of the R.R.S. Discovery II}

$\mathrm{T}$ HE Discovery Committee's vessel R.R.S. Discovery $I I$, built in 1929 for oceanographical research in the Southern Ocean, returned to London from her fifth voyage on May 9. Leaving Fingland in October 1937, she spent the southern summer circumnavigating the antarctic continent, making observations along the northern edge of the pack-ice south of the Indian, Pacific and Atlantic Oceans, and running lines of stations across the antarctic, subantaretic and subtropical regions as she came northwards to Australia, New Zealand and the Falkland Islands for fuel.

In the subtropical and subantarctic regions a full station was worked every day : temperatures were measured and water samples taken at a series of depths between the surface and the bottom, and nets were fished to depths of at least 1,000 metres. In the antarctic zone extra nets were fished to obtain a more complete picture of the distribution of the small prawn-like krill (Euphausia superba) on which the whales feed, and a constant look-out was kept for whales. Near the ice-edge, and in regions where the krill are known to breed, the work was still more intensive.

A qualitative picture of the water circulation in the Southern Ocean and the distribution of factors that influence plant and animal growth had been obtained on previous voyages, and although this latest voyage extended the work whenever possible, its main object was the collection of data for comparison with previous observations, particularly in regard to the contrast between summer and winter conditions. The circumpolar voyage was completed early in May 1938, and the remainder of the commission was devoted to the systematic survey, month by month, of a limited section of the Southern Ocean. Such repeated observations are of great assistance in the elucidation of oceanographical problems, and it is noteworthy that the International Council for the Exploration of the Sea is planning a similar though more concentrated survey of the Faroe - Shetland region.

The area chosen was the antarctic sector between the Greenwich meridian and $20^{\circ} \mathrm{E}$. : this afforded a good opportunity for the examination of typical antarctic, subantarctic and subtropical conditions, and at the same time it allowed a continuous examination of the terminal region of the. Weddell Sea current, a matter of great importance, since the Weddell Sea has been found to be by far the greatest centre of production of krill.

After refitting in Simonstown, the Discovery II steamed southwards along the Greenwich meridian as far as the ice-edge, and after a short cruise away from the ice to a point some 300 miles to the northward in $10^{\circ} \mathrm{E}$., she returned northwards along $20^{\circ} \mathrm{E}$. Between July 1, 1938, and Murch 19, 1939, this voyage, south and north, was made seven times, and 
altogether within the last two and a half years the $0^{\circ}$ line has been examined eleven times.

The preliminary examination of the repeated observations shows that there are important changes from month to month, particularly at the surface; but - and the discovery is a matter for great satisfaction-the changes in the deep water are not large enough to invalidate a qualitative picture of the water circulation drawn from observations made on only one or two occasions. It is hoped that a closer examination of the repeated observations will give reliable quantitative information, and that many problems - chiefly those connected with the speeds of the water and plankton movements-will be brought nearer solution.

The data and collections obtained, a valuable supplement to those of earlier voyages, have been brought to England, and the scientific staff are settling down to what it is hoped will be a very productive period.
The pressure of the scientific work on the fifth commission left little time for survey work, but charts have been prepared of the Balleny Islands, and of the antarctic coastline between the Greenwich meridian and $4 \frac{1}{2} \mathrm{E}$. Along this part of the coast there is a very narrow shelf, and in one place the ice. barrier was found to protrude beyond the 1,000 . fathom line. One bay, however, that was entered was found to end in a low ice-shelf 10 feet high with a sounding of 60 fathoms within a distunce of three cables; behind the bay snow-covered slopes rose gradually to $2,000 \mathrm{ft}$. The only exposed rock seen along the whole coastline was one snow-free boulder, and a small exposure at the foot of a shoulder.

The ship was commanded by Captain Hill, and Mr. Herdman was the senior scientific investigator on board. In addition to the Committee's own staff, Australian, New Zealand and South African scientific workers were carried for some parts of the com. mission.

\section{Glass Technology at Sheffield}

\section{New Buildings}

$\mathrm{T}$ HE Department of Glass Technology in the University of Sheffield came into being as a result of a scientific advisory committee set up by the University of Sheffield in 1914. The Department was founded in June 1915 and existed by courtesy in various rooms in the University buildings. A small building to deal with experimental work was erected and occupied without any formality early in 1917 , but growth and the need for returning borrowed accommodation to its rightful owners on the conclusion of the Great War compelled a move to other premises some distance from the University buildings in 1921. It was always felt that such a move could only be temporary, but not until 1935 was a suitable site found to house the Department in a worthy manner. This was acquired in 1936, the twenty-first anniversary year of the Department, and the appeal for funds called forth a most gratifying response. In addition to the subscriptions of more than $£ 37,000$ to the Glass Delegacy's fund, the Society of Glass Technology has contributed $£ 2,600$ towards the cost of the lecture theatre and adjacent rooms, and old students and staff have furnished the professor's room. The Frank Wood Library also was the subject of a special fund of some $£ 1,150$.

On Monday, June 12, the new buildings were formally opened by the Right Hon. Lord Riverdale of Sheffield, chairman of the Advisory Council for Scientific and Industrial Research, after dedication by the Right Rev. the Lord Bishop of Sheffield.

In his remarks, Lord Riverdale emphasized that one of the prime needs of the world to-day is confidence. Such confidence in the Glass Department has been felt by the industry that these new buildings are the result. What began as a local movement is now not only national but also international, for the Society of Glass Technology draws its members from all over the world and works in harmony with other similar bodies abroad.

The actual opening ceremony consisted of the drawing apart of curtains woven from glass silk hung before the main doorway. Mr. Geoffrey Pilkington then unveiled a tablet in the porch commemorating the opening, after which a degree congregation was held in the Museum for the purpose of conferring the degree of LL.D. on Mr. S. B. Bagely, the chairman of the Glass Delegacy, and of Ph.D. on Mr. B. P. Dudding, who as president of the Society of Glass Technology that year launched the Society's Elmfield Fund. The vice-chancellor, Dr. Irvine Masson, said that the building is a monument to the good relations between the University and the glass industry. Its products would be two-new knowledge and scientifically trained men.

The president of the Society of Glass Technology, Dr. C. J. Peddle, next unveiled in the lecture theatre a tablet bearing the names of the donors to the Society's fund, and the ceremonies were pleasantly concluded by the presentation to Lord and Lady Riverdale of a glass rose bowl by Mrs. W. E. S. Turner, and a speech of thanks by Prof. Turner, to whom many tributes were paid during the day's proceedings.

Afterwards the Department was inspected by the guests. It is situated in two and three quarter acres of attractive grounds overlooking on either side small reservoirs and is about six minutes' walk from the main University buildings. The original stonebuilt house has been retained to form an adminis. trative section. It contains on the ground floor an entrance hall with a pair of stained glass windows by Mr. S. M. Scott depicting glass makers at work and will house later a large tablet with illustrations of great achievements by English glass makers during three centuries and bearing the names of donors to the Glass Delegacy's Fund. In the porch is a glass-fronted niche containing a glass casket which holds historic records. Opening off the entrance hall are the conference room, the professor's room and the visitor's room. On the first floor is the Frank Wood Library, containing a stained glass window in memory of Mr. Frank Wood, a librarian's room, 